\title{
Quantitation and kinetic properties of hepatic microsomal and recombinant flavin-containing monooxygenases 3 and 5 from humans
}

\author{
Lila H. Overby, Geraldine C. Carver, Richard M. Philpot* \\ Laboratory of Signal Transduction, National Institute of Environmental Health Sciences, \\ Research Triangle Park, NC 27709, USA
}

Received 1 May 1997; received in revised form 23 June 1997; accepted 8 July 1997

\begin{abstract}
Variable amounts of flavin-containing monooxygenase isoforms 3 and 5 (FMO3 and FMO5) are present in microsomal preparations from adult, male, human liver. Quantitation with monospecific antibodies and recombinant isoforms as standards showed levels of FMO3 and of FMO5 that ranged from 12.5 to 117 and 3.5 to $34 \mathrm{pmol} / \mathrm{mg}$ microsomal protein, respectively. The concentration of FMO3 was greater than that of FMO5 in all samples, but the ratio of FMO3 to FMO5 varied from 2:1 to 10:1. Human hepatic microsomal samples also showed variable activities for the S-oxidation of methimazole. This activity was associated totally with FMO3; no participation of FMO5 was apparent. This conclusion was supported by several lines of evidence: first, the catalytic efficiency of FMO3 with methimazole was found to be $\sim 5000$ times greater than that of FMO5; second, the rate of metabolism showed a direct, quantitative relationship with FMO3 content; third, the plot of the relationship between metabolism and FMO3 content extrapolated close to the origin. A second reaction, the N-oxidation of ranitidine, exhibited a much higher $K_{\mathrm{m}}$ with recombinant FMO3 than did methimazole $(2 \mathrm{mM}$ vs. $35 \mu \mathrm{M})$. However, a direct relationship between this reaction and FMO3 content in human hepatic microsomal preparations was also apparent. This result shows that even with a high $K_{\mathrm{m}}$ substrate, FMO3-catalyzed metabolism can account for the majority of the product formation with some drugs. Our findings demonstrate that the contribution of FMO isoforms to human hepatic drug metabolism can be
\end{abstract}

* Corresponding author.

0009-2797/97/\$17.00 (C) 1997 Elsevier Science Ireland Ltd. All rights reserved.

PII S0009-2797(97)00055-0 
assessed quantitatively on the basis of the characteristics of the enzymes expressed in Escherichia coli (C) 1997 Elsevier Science Ireland Ltd.

Keywords: FMO3; FMO5; Drug metabolism; Ranitidine; Methimazole

\section{Introduction}

The flavin-containing monooxygenase (FMO) gene family contains five members that are expressed in a species- and tissue-dependant manner [1]. These enzymes catalyze the oxidative metabolism of a variety of nitrogen-, sulfur-, and phosphorous-containing compounds, some of which are of toxicological importance $[2,3]$. The involvement of FMO-mediated reactions in human drug metabolism has been associated with a number of substrates including dimethylaniline [4-6], tertiary amines [7,8] including imipramine [6] and chlorpromazine [9], thiobenzamide [5,6], and tamoxifen [10].

The most thoroughly studied of the FMO isoforms are FMO1, the major form expressed in liver of adult pigs [1], and FMO2, the major form in lung of adult rabbit [11]. However, neither of these isoforms appears to be expressed to any significant extent in the adult human liver [12]. On the basis of catalytic, immunochemical and expression data, it has been suggested that FMO3 makes the greatest contribution to FMO-mediated drug metabolism in adult human liver [12-15]. FMO3 has been cloned from human [13] and rabbit [16] and purified from rabbit [17], and FMO3 orthologs from macaque [14] and rat [18] have been identified. Results with purified and recombinant FMO3 $[14,19,20]$ and with human samples $[21,22]$ have provided evidence that the unique stereoselectivity of human liver microsomes for the metabolism of prochiral FMO substrates is a function of FMO3. However, FMO3 has not been quantitated in human samples nor has its specific activity (catalytic constant) been determined.

In addition to FMO3, FMO5 has also been detected in human liver [23]. While the activity of FMO5 appears to be limited by low substrate affinity, its concentration in human liver and its ability to metabolize known FMO drug substrates have not been investigated. Transcript for FMO4 has been detected in samples from human liver [24], but no evidence for protein expression has been reported. Therefore, it appears that the major FMO enzymes in human liver are FMO3 and FMO5. We have now examined the kinetic properties of FMO3 and FMO5 expressed in Escherichia coli and have been able to associate these properties with FMO activities in human liver microsomal samples. Quantitation of FMO3 and FMO5 with monospecific antibodies has allowed for a direct relationship to be established between FMO3 concentration and FMO-mediated activity. In addition, the results show little relationship between the expression of FMO3 and FMO5 and no relationship between levels of mRNA and levels of enzyme. 


\section{Methods and materials}

\subsection{Cloning and sequencing of human FMO3 and FMO5}

Human FMO5 was cloned from a human hepatic library and sequenced as described by Overby et al. [23]. Several cDNA clones encoding human FMO3 were isolated from the same library by hybridization with a $620 \mathrm{bp} 5^{\prime}$-fragment (Eco RI) of the cDNA for rabbit FMO3 [16] random labelled [25] with ${ }^{32} \mathrm{PdCTP}$ (Boehringer Mannheim, Indianapolis, IN). Plaque lifts were prehybridized and hybridized in $6 \times$ SSC, salmon sperm $100 \mathrm{mg} / \mathrm{ml}, 4 \times$ Denhardt, $0.5 \%$ SDS and $50 \%$ formamide. Subsequent to overnight hybridization at $37^{\circ} \mathrm{C}$, the lifts were washed twice under conditions of low stringency $(1 \times \mathrm{SSC} 0.1 \% \mathrm{SDS})$ for $30 \mathrm{~min}$ at $37^{\circ} \mathrm{C}$. Fifteen positive plaques were isolated to purity and characterized by restriction mapping based on published sequences [13,16,23] and end sequencing with T3 and T7 primers. Seven clones containing complete coding regions were identified - four encoding FMO3, two FMO5, and one FMO4. Oligonucleotide primers were used to obtain the sequence of FMO3 from both strands of three full-length clones [26]. Sequence data was analyzed and aligned with the software package from Genetics Computer Group [27]. Comparison of our sequence with those reported by others $[13,24]$ has been reported elsewhere [28].

\subsection{Expression of human FMO3 and FMO5 in E. coli}

Plasmid DNA of clone 17 (FMO3) was restricted with $S c a$ I for $1 \mathrm{~h}$ and $N c o$ I for $3 \mathrm{~min}$. The $\mathrm{Nco} / \mathrm{Sca}$ I fragment, which spans from one base $5^{\prime}$ of the start codon to 115 bases $3^{\prime}$ of the stop codon $(1.717 \mathrm{~kb})$, was isolated, purified and ligated into the expression vector pJL-2 [29] restricted with $N c o$ I and Eco RV. The construct (FMO3-pJL) was used to transform E. coli (strain XL-1). The construction of FMO5-pJL has been described [23]. Expression of FMO3 and FMO5 in E. coli was carried out as described for FMO5 [23].

\subsection{Preparation of membrane fractions}

Microsomal fractions were prepared from samples of human liver by the Drug Metabolism Division of Glaxo, (Glaxo-Wellcome, Research Triangle Park, NC). The liver tissue was obtained from the International Institute for the Advancement of Medicine (IIAM) and Stanford Research Institute. The samples were from four adult male Caucasians ( \# 437, 57 years old; \# 300, 42 years old; \# 8, 39 years old; and \# 58, 58 years old) and one adult black male (\# 405, 47 years old). Microsomal fractions were prepared by the method of Sadeque et al. [14]. Inclusion of EDTA $(10 \mathrm{mM})$ in the homogenization buffer and EDTA $(100 \mu \mathrm{M})$ and glycerol $(20 \%)$ in the storage buffer was required for maximum activities and for maintenance of activities during storage. The $100000 \mathrm{~g}$ membrane fraction from E. coli was obtained by the procedure of Lawton et al. [30]. 


\section{Purification of recombinant rabbit FMO3 and FMO5 and preparation of monospecific antibodies}

E. coli containing recombinant rabbit FMO3 or FMO5 was recovered from 1-2 1 of medium, and the membrane fraction was prepared [30]. Purification of FMO3 and FMO5 from detergent-solubilized preparations was done by fractionation with polyethelene glycol and chromatography on DEAE cellulose as described by Overby et al. [23]. Antibodies were raised in goats and their specificity tested with recombinant FMO1, 2, 3, and 5. Antibodies to FMO5 (anti-5) did not cross-react with other FMO isoforms and were used without further processing. Antibodies to FMO3 (anti-3), which recognized all FMO isoforms, were made monospecific by reaction with $E$. coli membrane fractions containing recombinant FMO1, FMO2, or FMO5 bound to nitrocellulose. Neither anti-3 nor anti-5 cross-reacts with FMO4 (Itagaki et al., personal communication, manuscript in preparation).

\subsection{Metabolism of methimazole, ranitidine and cimetidine}

Metabolism of methimazole catalyzed by recombinant FMO3 or FMO5 and by human microsomal fractions was determined spectrophotometrically (Aminco DW2A UV/VIS spectrophotometer) in $0.1 \mathrm{M}$ Tricine ( $\mathrm{pH}$ 8.4), $1 \mathrm{mM}$ EDTA [31]. The substrate concentration used was $1 \mathrm{mM}$ unless stated otherwise. Kinetic determinations were made with concentrations of methimazole from $5 \mu \mathrm{M}$ to 2 $\mathrm{mM}$. Metabolism of ranitidine $(100 \mu \mathrm{M}$ to $5 \mathrm{mM})$ or cimetidine $(100 \mu \mathrm{M}$ to $3 \mathrm{mM})$ catalyzed by recombinant FMO3 was calculated from rates of NADPH oxidation. NADPH oxidation was determined at $360 \mathrm{~nm}$ (Aminco DW2A spectrophotometer) because of substrate interference at $340 \mathrm{~nm}$. A molar extinction coefficient of 4360 was used. Ranitidine and cimetidine were also assessed as inhibitors of methimazole metabolism. Rates of ranitidine N-oxidation in human hepatic microsomal or recombinant preparations were determined by HPLC analysis (YMC ODS-AM column) of metabolites at a ranitidine substrate concentration of $1 \mathrm{mM}$. Metabolites were separated with a linear gradient $(4-10 \%)$ of acetonitrile run for $15 \mathrm{~min}$., $10 \%$ acetonitrile for $7 \mathrm{~min}$, a linear gradient (10-20\%) of acetonitrile run for $2 \mathrm{~min}$,, and $20 \%$ acetonitrile. The running buffer was sodium citrate ( $\mathrm{pH} 7.2,50 \mathrm{mM}$ ). Metabolites were identified by LC/MS and quantitation was done with authenticated standards. A complete analysis of the human hepatic microsomal metabolism of ranitidine will be published elsewhere. Incubations with human samples contained 1 or 10 to $50 \mathrm{mg}$ microsomal protein for metabolism of rantidine or methimazole, respectively.

\subsection{Preparation and analysis of $m R N A$}

Total RNA was isolated from samples of human liver by a modification [32] of the methods of Chirgwin et al. [33] and Glisin et al. [34], and mRNA was purified according to Aviv and Leder [35]. Samples of mRNA were electrophoresed in 1\% agarose gels containing $0.5 \%$ methyl mercury [36], transferred to nylon membranes, 
and baked. The membranes were prehybridized for a minimum of $4 \mathrm{~h}$ at $42^{\circ} \mathrm{C}$, then hybridized with a human FMO5 probe (Pst $\mathrm{I} / N c o \mathrm{I}$, bases 1-1379) or a human FMO3 probe $(E c o \mathrm{RI} / X$, bases $1007-2106)$ labelled by the random primer method $\left(5 \times 10^{6} \mathrm{cpm} / \mathrm{ml}\right)$, at $37^{\circ} \mathrm{C}$ overnight. Hybridized membranes were washed at $42^{\circ} \mathrm{C}$ for $2 \times 30 \mathrm{~min}$ in $1 \times \mathrm{SSC} / 0.1 \% \mathrm{SDS}$ solution, and exposed to autoradiography film at $-70^{\circ} \mathrm{C}$ for $1-3$ days. Relative levels of mRNA were assessed with a digital imaging system (IS-1000, Alpha Innotech, San Leandro, CA) and programming supplied by the NIH (NIH Image 1.59). As has been reported, a single band of hybridization $(\sim 2.3 \mathrm{~kb})$ was detected for FMO3 [13] and two bands $(\sim 2.6$ and 3.8 $\mathrm{kb})$ were detected for FMO5 [23].

\subsection{Quantitation of FMO3 and FMO5}

The concentrations of FMO3 and FMO5 in human hepatic microsomal samples were determined by immunoblotting with recombinant enzymes in membrane preparations as standards. Linear relationships between staining intensity and the concentration of recombinant enzymes (FMO3, 50 to $350 \mathrm{fmol}$; FMO5, 13.4 to 404 fmol) were established. These relationships were used to determine the FMO3 and FMO5 concentration in human microsomal sample 405. Sample 405 was then used as a standard for the analysis of the microsomal preparations. Concentrations of FMO3 and FMO5 were calculated from results with three concentrations of microsomal protein. Immunostaining was assessed by densitometry with a digital imaging system (IS-1000, Alpha Innotech, San Leandro, CA) and programming supplied by the NIH (NIH Image 1.59).

\subsection{Analytical methods}

Membrane proteins were subjected to polyacrylamide gel electrophoresis in the presence of SDS [37] and analyzed by staining with Coomassie Blue or by immunoblotting following transfer to nitrocellulose [38]. Samples were not boiled prior to electrophoresis. The staining intensities with samples that had been boiled was reduced significantly. Immunoblots were stained with antibodies (goat $\mathrm{IgG}$ ) to rabbit FMO3 or rabbit FMO5 purified from E. coli by the method described previously [23]. FAD contents were determined in washed particulate fractions by the method of Faeder and Siegel [39] and protein concentrations were determined by the method of Lowry et al. [40].

\section{Results}

\subsection{Expression of FMO3 and FMO5 in E coli}

Particulate fractions (100000 g) from E. coli transformed with FMO3, FMO5, and $\mathrm{pJL}$ alone were electrophoresed on polyacrylamide gels in the presence of SDS and stained for protein with Coomassie Blue. The protein band with the highest 
intensity of staining in the FMO3 or FMO5 samples was not present in the pJL sample (Fig. 1). The extent of expression of FMO3 or FMO5 was estimated by determination of flavin concentrations and was based on an assumption of 1 mole of FAD bound per mole of FMO. E coli from three separate experiments with FMO3 contained $0.60,0.34$, and $0.40 \mathrm{nmol} F A D / m g$ protein in excess of the control ( $\mathrm{pJL}$ alone) level. The corrected FAD concentrations in two preparations of FMO5 were 1.22 and $1.31 \mathrm{nmol} \mathrm{FAD} / \mathrm{mg}$ protein. These FAD concentrations indicate that FMO3 and FMO5 accounted for 2 to $4 \%$ and 7 to $8 \%$, respectively, of the E. coli $100000 \mathrm{~g}$ protein.

\subsection{Characterization of human FMO3 and FMO5}

The activities of recombinant FMO3 and FMO5 were examined with methimazole as the substrate. Both enzymes catalyzed the S-oxidation and showed a relationship between substrate concentration and rate of reaction consistent with

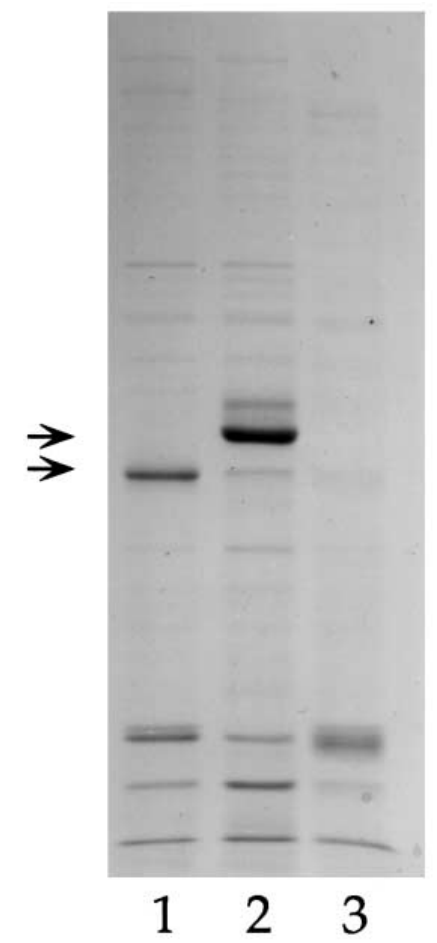

Fig. 1. Expression of human FMO3 and FMO5 in E. coli. E. coli (strain JM109) were transformed with FMO3, FMO5 or vector (pJL2) alone. Particulate fractions (100000 g) were prepared and samples (5 $\mu \mathrm{g}$ ) were electrophoresed on polyacrylamide gel in the presence of SDS and stained with Coomassie Blue. Expression of FMO3 (lane 1) and FMO5 (lane 2) is designated by the arrows. E. coli transformed with vector alone is shown in lane 3 . 
A

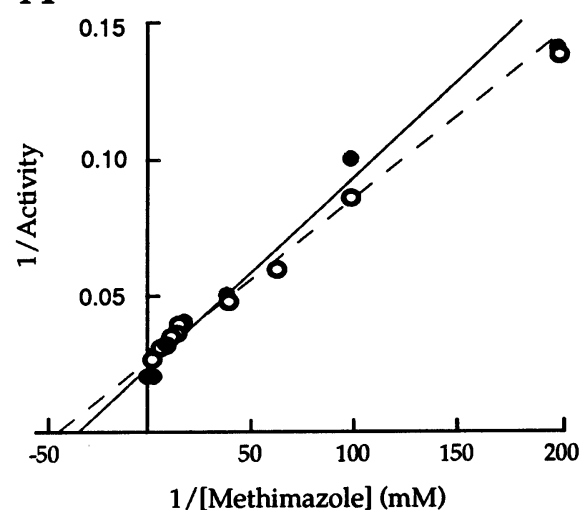

B

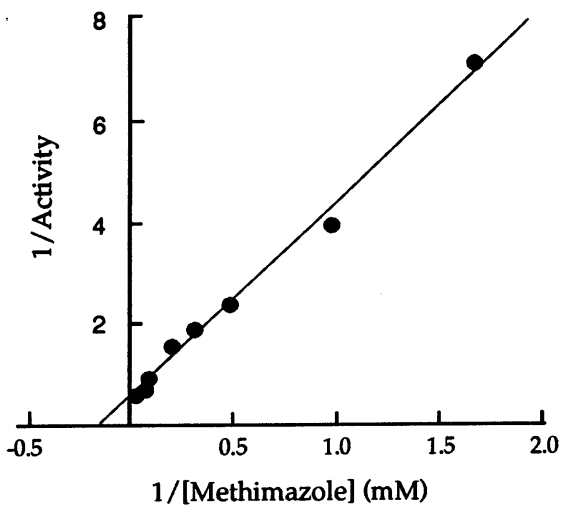

Fig. 2. Metabolism of methimazole catalyzed by human FMO3 or human FMO5. Lineweaver-Burke plots show the relationship between the inverse of activity (nmol product/nmol FMO per min) and the inverse of methimazole concentration of $(1 / \mathrm{mM})$ for the reaction catalyzed by recombinant FMO3 (A,-- - ) or FMO5 (B). Results are also shown for the reaction catalyzed by human hepatic microsomal sample 8 (A, $\bigcirc--\bigcirc)$.

Michaelis-Menten kinetics (Fig. 2, A and B). However, FMO3 $\left(K_{\mathrm{m}}=35 \mu \mathrm{M}\right.$, $V_{\max }=50 \mathrm{nmol}$ product $/$ min per nmol FMO3) was found to be about $5 \times 10^{3}$ times more efficient than FMO5 $\left(K_{\mathrm{m}}=6 \mathrm{mM}, V_{\max }=1.4 \mathrm{nmol}\right.$ product $/ \mathrm{min}$ per nmol FMO5) in catalyzing the reaction. (Microsomal data shown in Fig. 2A is discussed below). A summary of all kinetic constants calculated is presented in Table 1.

Table 1

Kinetic constants for metabolism of methimazole, ranitidine and cimetidine catalyzed by human FMO3 and FMO5 expressed in E. coli ${ }^{\mathrm{a}}$

\begin{tabular}{|c|c|c|c|c|c|}
\hline Isoform & Substrate & Inhibitor & $K_{\mathrm{m}}(\mathrm{mM})$ & $K_{\mathrm{i}}(\mathrm{mM})$ & $V_{\max }^{\mathrm{b}}$ \\
\hline FMO3 & Methimazole & & 0.035 & & 50 \\
\hline FMO5 & Methimazole & & 6 & & 1.4 \\
\hline FMO3 & Ranitidine & & 2 & & 17 \\
\hline FMO3 & Cimetidine & & 4 & & 15 \\
\hline FMO5 & Ranitidine & & $>10$ & & n.d. \\
\hline FMO5 & Cimetidine & & $>10$ & & n.d. \\
\hline FMO3 & Methimazole & Ranitidine & & 2 & \\
\hline FMO3 & Methimazole & Cimetidine & & 5 & \\
\hline FMO5 & Methimazole & Ranitidine & & $>10$ & \\
\hline FMO5 & Methimazole & Cimetidine & & $>10$ & \\
\hline
\end{tabular}

${ }^{a}$ Metabolism of methimazole was determined by product formation and metabolism of ranitidine and cimetidine by NADPH oxidation.

${ }^{\mathrm{b}}$ The $V_{\max }$ units are nmol product/min per nmol FMO3 or FMO5. 

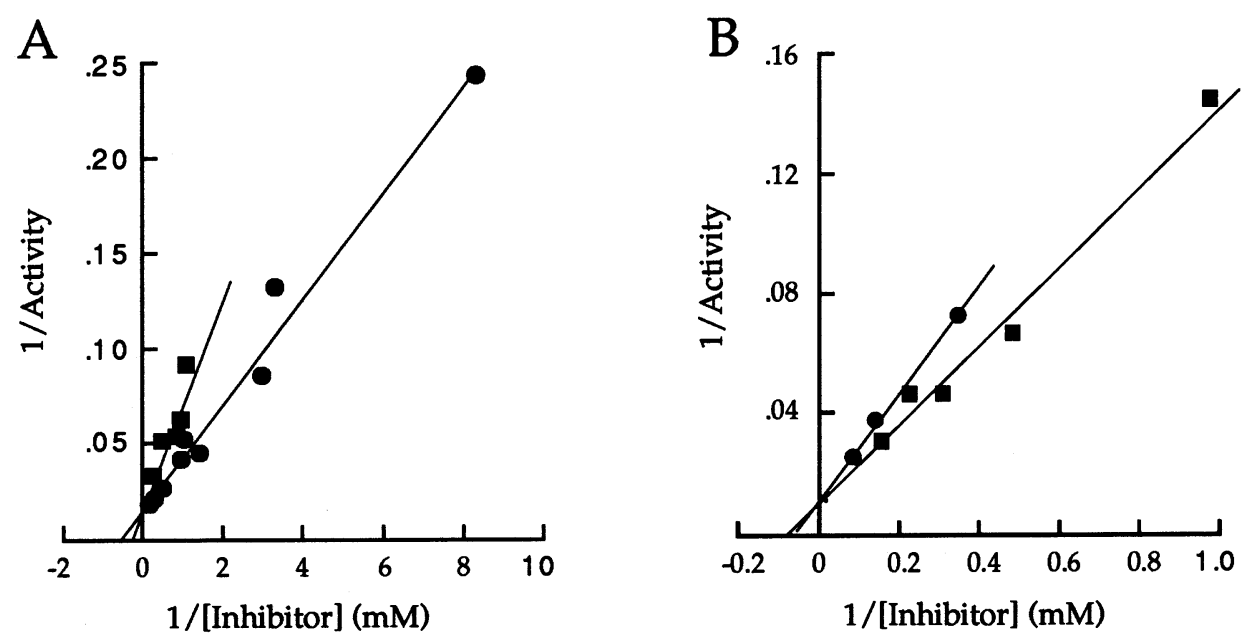

Fig. 3. Inhibition of recombinant FMO3 and FMO5 activity by ranitidine and cimetidine. FMO3 (A) or FMO5 (B) catalyzed metabolism of methimazole was inhibited by ranitidine $(\boldsymbol{\square})$ or cimetidine $(\bullet)$. The plots show the relationship between the inverse of activity, expressed as percent inhibited, and the inverse of the inhibitor concentration (mM). The methimazole concentration used was near the $K_{\mathrm{m}}(25$ $\mu \mathrm{M})$. Inhibition extrapolated to approximately $100 \%(1 / \mathrm{v}=0.01)$ in all cases.

\subsection{Metabolism of ranitidine and cimetidine by human FMO3 and FMO5}

The potential for FMO3 and FMO5 to catalyze the oxidation of ranitidine and cimetidine was determined initially by examining their effectiveness as inhibitors of methimazole metabolism. Based on kinetic analysis, both compounds acted as competitive inhibitors (not shown). Inhibitor constants $\left(K_{\mathrm{i}}\right)$ were determined from the relationship between the inverse of inhibitor concentration and the inverse of percent inhibition of the metabolism of methimazole at its $K_{\mathrm{m}}$ concentration. With FMO3 a $K_{\mathrm{i}}$ of $\sim 2 \mathrm{mM}$ was obtained for ranitidine and a $K_{\mathrm{i}}$ of $\sim 5 \mathrm{mM}$ for cimetidine (Fig. 3A). Inhibition of FMO5-catalyzed metabolism of methimazole by ranitidine and cimetidine occurred, but only at very high inhibitor concentrations (Fig. 3B). The $K_{\mathrm{i}}$ values for both compounds with FMO5 were estimated to be $>10 \mathrm{mM} . K_{\mathrm{m}}$ values determined from rates of FMO3-catalyzed oxidation of NADPH in the presence of ranitidine or cimetidine were $\sim 2 \mathrm{mM}$ and $\sim 4 \mathrm{mM}$, respectively (Fig. 4). The $K_{\mathrm{m}}$ values for FMO5-mediated NADPH oxidation with ranitidine and cimetidine could not be determined accurately because of substrate solubility problems but were clearly in excess of $10 \mathrm{mM}$.

The metabolism of ranitidine $(1 \mathrm{mM})$ catalyzed by recombinant FMO3 and FMO5 was assessed by HPLC. The N-oxide and S-oxide metabolites were both formed but no $\mathrm{N}$-demethylated product was detected. Rates of formation of the $\mathrm{N}$-oxide and S-oxide with FMO3 were $5.10 \pm 0.07$ and $0.98 \pm 0.02 \mathrm{nmoles} / \mathrm{min}$ per nmole enzyme. Rates of N-oxidation with FMO5 were less than $0.05 \mathrm{nmole} / \mathrm{min}$ per nmole enzyme (2-3 times background rates in incubations containing non-recombinant E. coli). 


\subsection{Quantitation of FMO3 and FMO5 protein and $m R N A$ in human liver samples}

Known amounts of recombinant FMO3 and FMO5, determined on the basis of flavin concentrations, were detected by immunoblotting (Fig. 5). The proteins detected had the same mobilities as expressed FMO3 and FMO5 shown in Fig. 1. Standard curves were constructed and used to quantitate FMO3 and FMO5 in human hepatic microsomal preparations. The curves were linear for FMO5 $\left(r^{2}=\right.$ $0.99)$ over the concentration range used (13.4-404 fmol) and for FMO3 $\left(r^{2}=0.97\right)$ between 25 and 300 fmol. Positive identification of FMO3 or FMO5 was provided by monospecific antibodies that detected single protein bands with mobilities matching those of expressed FMO3 or FMO5. Calculations were based on slopes obtained from results of immunodetection with three concentrations of microsomal protein (Fig. 6). As shown for FMO3 in Fig. 7, a linear relationship between protein concentration and intensity of staining was observed. The concentrations of FMO3 and FMO5 in five human hepatic microsomal preparations were highly variable - 12.5-117 $\mathrm{pmol} / \mathrm{mg}$ protein for FMO3 and 3.5-34 pmol $/ \mathrm{mg}$ protein for FMO5 (Table 2). Ratios of FMO3 to FMO5 ranged from 1.9 to 9.6 , and only a weak relationship between FMO3 and FMO5 contents was apparent $(r=0.75)$. Relative amounts of mRNA for FMO3 and FMO5 in samples of RNA from the five human livers were also highly variable (Fig. 8, Table 2). However, the mRNA levels were, if anything, somewhat inversely related to the protein concentrations $(r=-0.58$ for FMO3 and -0.52 for FMO5). Little or no agreement between the relative amounts of mRNA for FMO3 and FMO5 was observed $(r=0.52)$.

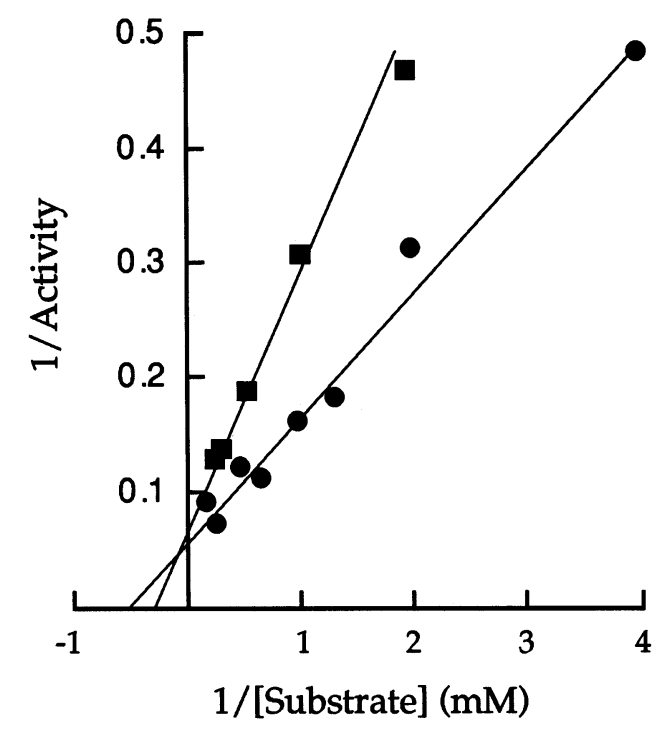

Fig. 4. Metabolism of ranitidine and cimetidine catalyzed by recombinant human FMO3. The Lineweaver-Burke plot shows the relationship between the inverse of activity (nmol NADPH oxidized/ nmol FMO3 per min) and the inverse of substrate concentration $(\mathrm{mM})$ for ranitidine ( $\mathbf{0})$ and cimetidine 


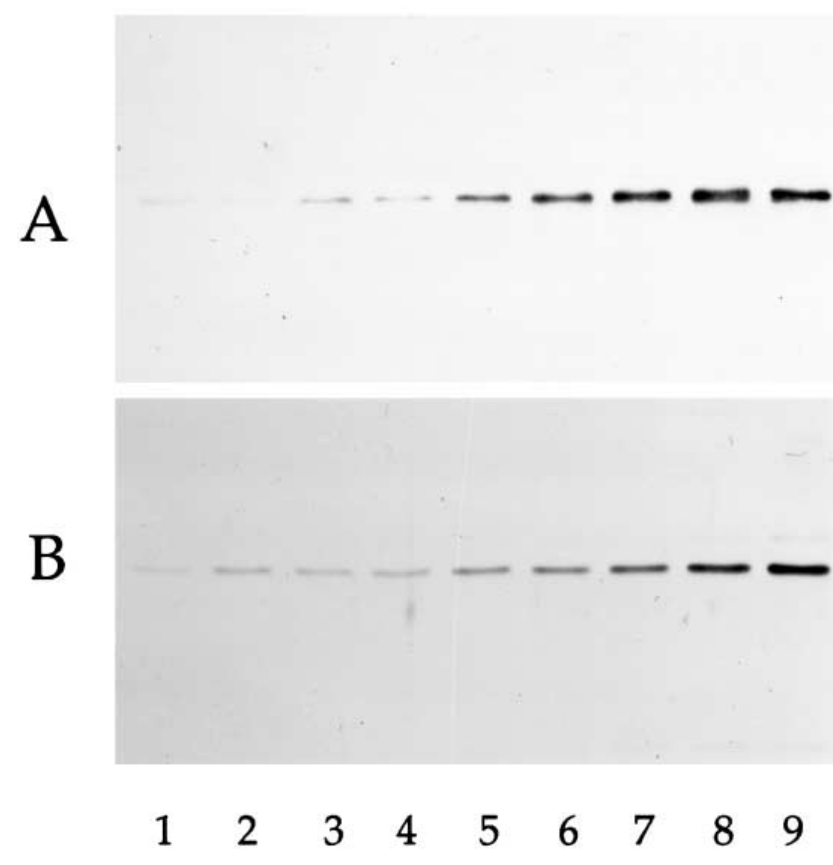

Fig. 5. Immunodetection of recombinant FMO3 and FMO5. FMO3 (A) or FMO5 (B) present in the $100000 \mathrm{~g}$ particulate fraction from $E$. coli was detected by the immunoblotting technique described in the Section 2. The amounts (fmoles) of FMO3 or FMO5 present were 25 or 13.4 (lane 1), 50 or 26.8 (lane 2), 75 or 40.2 (lane 3), 100 or 67.0 (lane 4), 150 or 98.8 (lane 5), 200 or 134 (lane 6), 250 or 197.5 (lane 7), 300 or 314.2 (lane 8) and 350 or 404 (lane 9).

\subsection{FMO-catalyzed metabolism in human hepatic microsomal samples}

FMO-catalyzed metabolism of methimazole (S-oxidation) and ranitidine (N-oxidation) varied significantly among the five human hepatic microsomal samples; $0.9-5.7$ and $0.13-0.76 \mathrm{nmol} / \mathrm{mg}$ protein per min, respectively (Table 2). However, agreement between the rates of metabolism in each sample was excellent $(r=0.95)$, and each rate was directly proportional to the FMO3 concentration $(r=0.99$ with methimazole and 0.93 with ranitidine) as shown in Fig. 9. A kinetic plot for methimazole metabolism with a single preparation (sample 8) is shown in Fig. 2A. The kinetic parameters obtained $\left(K_{\mathrm{m}}=25 \mu \mathrm{M} ; V_{\max }=51\right.$ nmol/nmol FMO3 per min) were nearly identical to those calculated with recombinant FMO3. No evidence for the participation of a second enzyme in the reaction was observed even though sample 8 , which was used for the kinetic determinations, contained the highest relative concentration of FMO5 (34 vs. 78 $\mathrm{pmol} / \mathrm{mg}$ for FMO3). 


\section{Discussion}

Our results demonstrate that livers of adult, male humans contain highly variable amounts of FMO3 and FMO5. In five samples the total FMO3 plus FMO5 content ranged 10-fold, from a high of 150 to a low of $16 \mathrm{pmol} / \mathrm{mg}$ microsomal protein. FMO3 content was consistently greater than FMO5 content but the ratio of the two varied from 2:1 to 10:1. The variability in absolute levels of FMO3 we observed is somewhat greater than reported for relative levels of FMO3 determined immunochemically with an antibody to a macaque liver FMO [41].

Marked variability in FMO-dependent methimazole S-oxidation was also observed in samples from adult human liver, results consistent with those for a
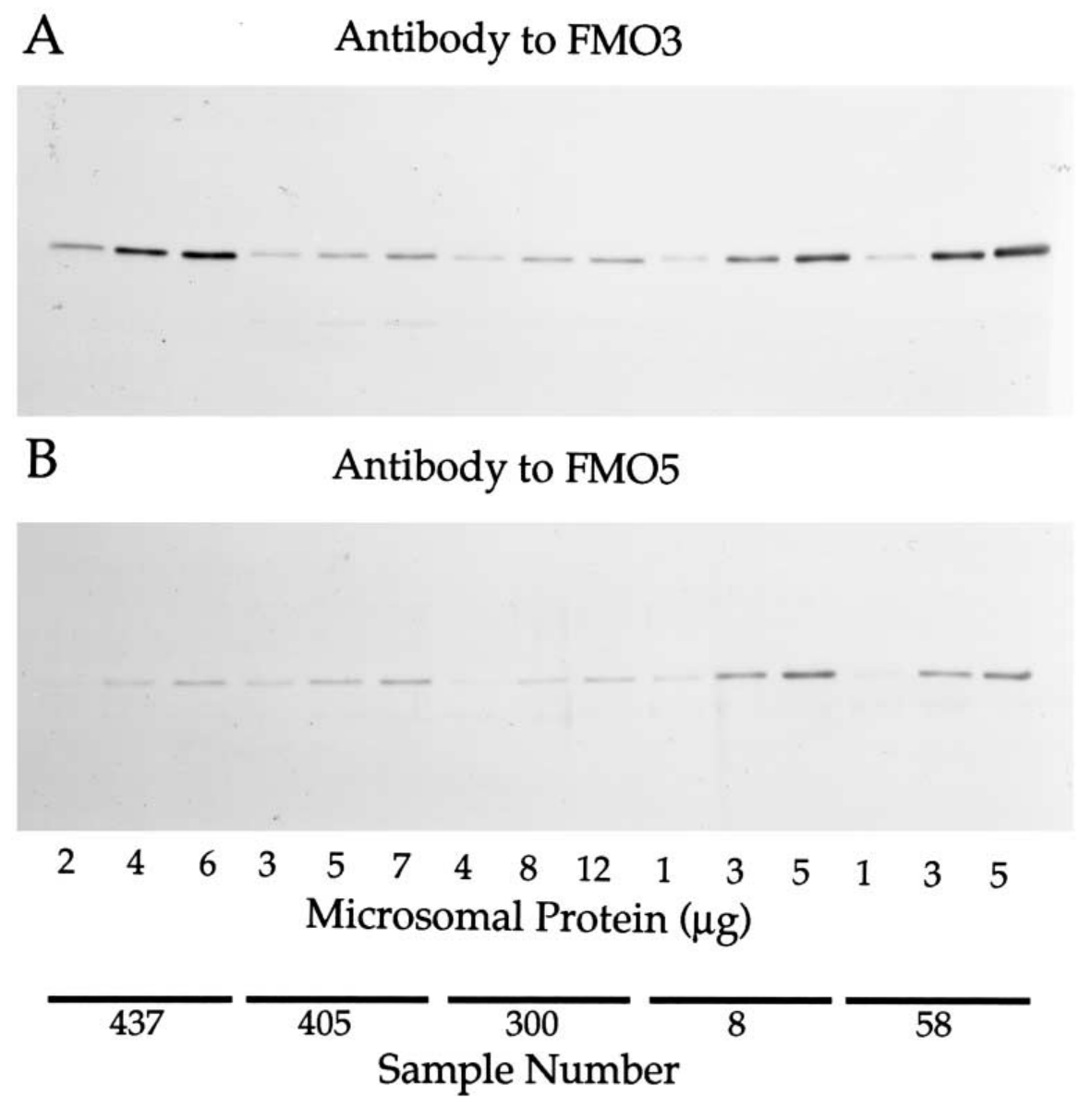

Fig. 6. Immunodetection of FMO3 and FMO5 in human hepatic microsomal samples. Microsomal samples from five human livers were subjected to SDS-PAGE, transfered to nylon, and stained using antibodies to FMO3 (A) or FMO5 (B). Three concentrations of each sample were used. Sample numbers and protein concentrations are shown in the figure. 


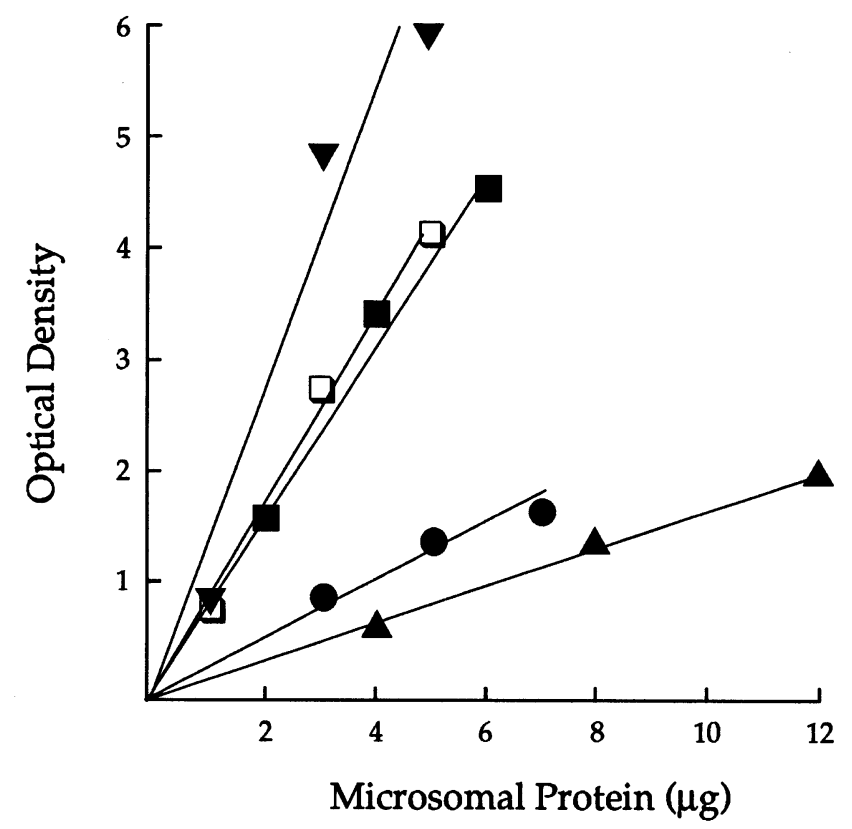

Fig. 7. Relationship between staining intensity of FMO3 in human hepatic microsomal samples and protein concentration. The intensity of the antibody staining was quantified by video analysis as described in Section 2 and plotted against the microsomal protein concentration. The samples were 437 $(\boldsymbol{\square}), 405(\bullet), 300(\mathbf{\Lambda}), 8(\square)$, and $58(\boldsymbol{\nabla})$.

number of FMO substrates $[4-6,21,41]$. The variability with methimazole appears to be entirely a function of FMO3 content $(r=.99)$. In addition, the nearly identical kinetic properties of microsomal FMO3 (quantitated by immunochemical analysis) and recombinant FMO3 (quantitated by flavin determination) indicates that our results were not compromised by loss of active enzyme during the preparation or storage of microsomal samples, a problem evidenced by levels of immunoreactive protein disproportionally greater than activities [21]. This finding provides a quantitative validation of the methods that have been developed for the preservation of FMO activities in human hepatic microsomal preparations [21,22,41] and the handling of hydrophobic proteins for use as immunochemical standards [42].

Regardless of the FMO3/FMO5 ratio, no kinetic evidence was found for the participation of FMO5 in the metabolism of methimazole. This is entirely consistent with the poor catalytic efficiency of FMO5 $(\sim 5000$ times less efficient than FMO3) determined with the recombinant enzyme. A lack of participation of FMO5 in the reaction is also supported by the observation that the relationship between the rate of methimazole oxidation and FMO3 content comes very close to extrapolating through the origin (Fig. 9).

Like S-oxidation of methimazole, N-oxidation of ranitidine also correlates quantitatively with FMO3 content. The high $K_{\mathrm{m}}$ value $(2 \mathrm{mM})$ for the N-oxidation of ranitidine by FMO3, which accounts for most, if not all of this activity in the 
Table 2

Levels of FMO3 and FMO5 immunoreactive protein and mRNA, and metabolism of methimazole and rantitidine in samples from human liver

\begin{tabular}{|c|c|c|c|c|c|c|}
\hline \multirow[t]{2}{*}{ Sample } & \multicolumn{2}{|c|}{$\begin{array}{l}\text { FMO content } \\
(\mathrm{pmol} / \mathrm{mg})^{\mathrm{a}}\end{array}$} & \multicolumn{2}{|c|}{$\begin{array}{l}\text { mRNA content } \\
\text { (relative) }^{\mathrm{b}}\end{array}$} & \multicolumn{2}{|c|}{$\begin{array}{l}\text { Metabolism } \\
(\mathrm{nmol} / \mathrm{mg} \text { per } \min )^{\mathrm{c}}\end{array}$} \\
\hline & FMO3 & FMO5 & FMO3 & FMO5 & Methimazole & Ranitidine \\
\hline 437 & 72.0 & 7.5 & 3411 & 1059 & 3.3 & 0.35 \\
\hline 405 & 22.0 & 11.5 & 4426 & 2777 & 1.6 & 0.29 \\
\hline 300 & 12.5 & 3.5 & 1778 & 2193 & 0.9 & 0.13 \\
\hline 8 & 78.0 & 34.0 & 1074 & 945 & 4.1 & 0.42 \\
\hline 58 & 117.0 & 30.0 & 534 & 1450 & 5.7 & 0.76 \\
\hline
\end{tabular}

a The concentrations of FMO3 and FMO5 were determined by immunochemical analysis with recombinant enzyme as the standards as described in Section 2.

${ }^{b}$ Relative amounts of mRNA were determined by Northern analysis as described in Section 2. Relative amounts of mRNA for FMO3 and FMO5 are not comparable.

${ }^{\mathrm{c}}$ Metabolism of methimazole and ranitidine were achieved by determination of product formation as described in Section 2.

samples we examined, is consistent with the low overall metabolism of ranitidine in man [43]. Low affinity $\left(K_{\mathrm{m}} 1-2 \mathrm{mM}\right)$ FMO-catalyzed formation of ranitidine $\mathrm{N}$-oxide has also been reported for dog, rat, and guinea pig [43]. In the case of the

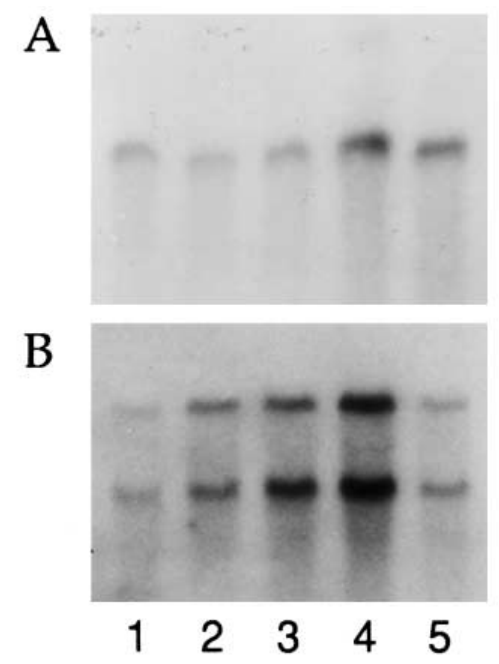

Fig. 8. Analysis of mRNA content in samples from human liver. (A) Hybridization of mRNA samples $(5 \mathrm{mg}$ ) from human livers with a cDNA probe (bases 1007-2106) for FMO3. (B) Hybridization of mRNA samples (10mg) with a cDNA probe (bases 1-1379) for FMO5. The samples used were: lane 1, sample 58; lane 2, sample 8; lane 3, sample 300; land 4, sample 405, and lane 5, sample 437. Electrophoresis on agarose gels, transfer to nylon, hybridization and autoradiography were carried out as described in the Section 2. 


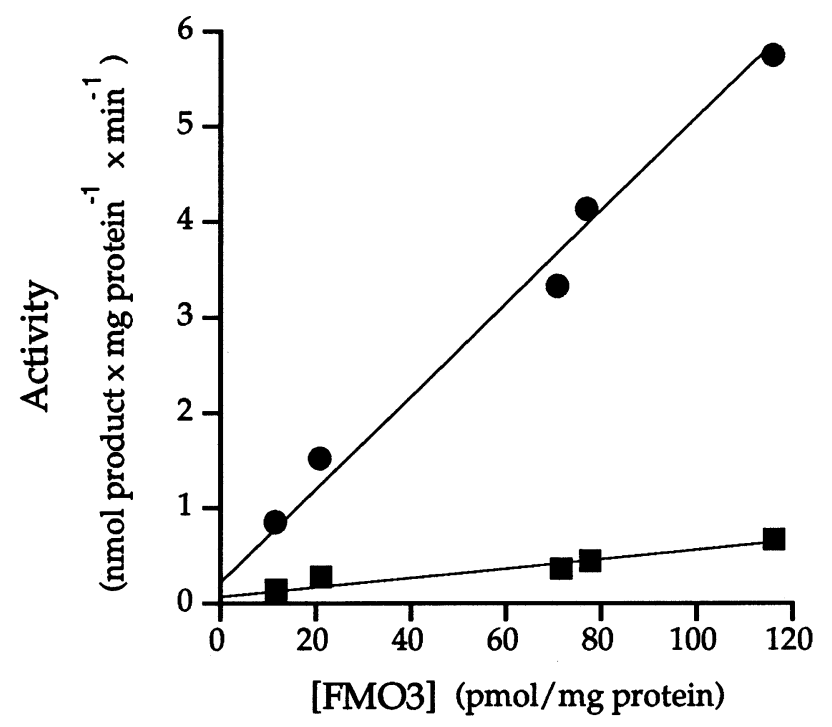

Fig. 9. Metabolism of methimazole and ranitidine as a function of FMO3 content in human hepatic microsomal incubations. The rates (nmol product $/ \mathrm{mg}$ microsomal protein per min) of metabolism of ranitidine ( $\boldsymbol{\square})$ and methimazole $(\bullet)$ are plotted against the concentration (pmol/mg protein) of FMO3. Data are for the five individual human samples described in Section 2.

rat and guinea pig, but not dog, a high affinity phase of N-oxidation was also observed [43]. Human FMO3 also catalyzes the S-oxidation of ranitidine, although at rates that are only about $1 / 5$ the rates of N-oxidation.

Notwithstanding the fact that differences in FMO-mediated metabolism in human hepatic samples appear to be explained by differences in FMO3 content, the most important question regarding this variability remains unanswered. Is it a reflection of individual differences or does it result from a range of values that might be obtained from a single individual over time? The lack of correlation between mRNA and enzyme levels among individuals suggests that the latter possibility deserves consideration. Unless the mechanisms regulating FMO content vary significantly among individuals, inherent differences in enzyme levels should be reflected by some steady state relationship between mRNA and protein. On the other hand, our results, which show a greater range in mRNA content for FMO3 than reported by Dolphin et al. [24], could be compromised by variable amounts of mRNA degradation. However, analysis of the protein/mRNA data suggests that this could only be the case if transcripts for FMO3 and FMO5 were affected quite differently in a given sample. A definitive answer to this question depends upon the development of a reliable in vivo metabolic determination that can be associated clearly with FMO3.

The conclusion that FMO3 is likely the major contributor to FMO-mediated activity in adult human liver has been reached in a number of studies [12-15,41,44]. Our results offer quantitative proof that this is indeed the case for the S-oxidation 
of methimazole and the N-oxidation of ranitidine. Given the general lack of activity of FMO5 $[23,43]$ this will likely hold true for the majority of substrates. The quantitative assessment of FMO3 and FMO5 in human liver microsomal preparations $(n=5)$ demonstrates the utility of the recombinant enzymes for such studies. It has been shown previously that recombinant FMO3 exhibits the general properties of an FMO [12] and that qualitative comparisons between recombinant and microsomal human FMO3 can be made $[45,46]$. We have now been able to demonstrate conclusively that the catalytic properties of the enzyme in the two systems are virtually identical and that quantitative assessment of FMO isoforms in human hepatic microsomal samples can be made on the basis of studies with recombinant enzyme.

\section{References}

[1] D.M. Ziegler, Flavin-containing monooxygenases: Catalytic mechanism and substrate specificity, Drug Metab. Rev. 19 (1988) 1-32.

[2] D.M. Ziegler, Recent studies on the structure and function of multisubstrate flavin-containing monooxygenases, Annu. Rev. Pharmacol. Toxicol. 33 (1993) 179-199.

[3] M. Al-Waiz, R. Ayesh, S.C. Mitchell, J.R. Idle, R.L. Smith, A genetic polymorphism of the N-oxidation of trimethylamine in humans, Clin. Pharmcol. Ther. 42 (1987) 588-594.

[4] M.S. Gold, D.M. Ziegler, Dimethylaniline N-oxidase and aminopyrene N-demethylase activities of human liver tissue, Xenobiotica 3 (1973) 179-189.

[5] M.E. McManus, I. Stupans, W. Burgess, J.A. Koenig, P de la M. Hall, D.J. Birkett, Flavin-containing monooxygenase activity in human liver microsomes, Drug Metab. Dispos. 15 (1986) 256-261.

[6] A. Lemoine, M. Johann, T. Cresteil, Evidence for the presence of distinct flavin-containing monooxygenases in human tissues, Arch. Biochem. Biophys. 276 (1990) 336-342.

[7] P. Hlavica, M. Lehnerer, Some aspects of the role of cytochrome P-450 isozymes in the N-oxidative transformation of secondary and tertiary amine compounds, J. Biochem. Toxicol. 10 (1995) $275-285$.

[8] R. Kuntzman, A. Phillips, I. Tsai, A. Klutch, J.J. Burns, N-oxide formation: a new route for inactivation of the antihistaminic chlorcyclizine, J. Pharmacol. Exp. Therap. 155 (1967) 337-344.

[9] P.F. Coccia, W.W. Westerfeld, The metabolism of chlorpromazine by liver microsomal enzyme systems, J. Pharmacol. Exp. Ther. 157 (1967) 446-458.

[10] C. Mani, E. Hodgson, D. Kupfer, Metabolism of the antimammary cancer agent tamoxifen II. Flavin-containing monooxygenase-mediated N-oxidation, Drug Metab. Dispos. 21 (1993) 657-661.

[11] M. Lawton, R.M. Philpot, Emergence of the flavin-containing monooxygenase gene family, Rev. Biochem. Toxicol.; E. Hodgson, J.R. Bend, R.M. Philpot (Eds.), Toxicology Communications, vol. 11, Raleigh, NC, 1995, pp. 1-27.

[12] I.R. Philips, C. Dolphin, P. Clair, M.R. Hadley, A.J. Hutt, R. McCombie, R.L. Smith, E.A. Shephard, The molecular biology of the flavin-containing monooxygenases of man, Chem.-Biol. Interact. 96 (1995) 17-32.

[13] N. Lomri, Q. Gu, J.R. Cashman, Molecular cloning of the flavin-containing monooxygenase (Form II) form adult human liver., Proc. Natl. Acad. Sci. USA 92 (1995) 9910.

[14] A.J.M. Sadeque, K.E. Thummel, A.E. Rettie, Purification of macaque liver flavin-containing monooxygenase: A form of the enzyme related immunochemically to an isozyme expressed selectively in adult human liver, Biochim. Biophys. Acta 1162 (1993) 127-134.

[15] J.R. Cashman, S.B. Park, Z-C. Yang, C.B. Washington, D.Y. Gomex, K.M. Giacomini, C.M. Brett, Chemical, enzymatic, and human enantioselective S-oxidation of cimetidine, Drug Metab. Dispos. 21 (1993) 587-597. 
[16] V.B. Burnett, M.P. Lawton, R.M. Philpot, Cloning, sequencing, and characterization of flavin-containing monooxygenases FMO3 and FMO4 from rabbit, J. Biol. Chem. 269 (1994) 14314-14322.

[17] J. Ozols, Isolation and structure of a third form of liver microsomal flavin monooxygenase, Biochemistry 33 (1994) 3751-3757.

[18] R.J. Krause, S.L. Ripp, P.J. Sausen, L. Overby, R.M. Philpot, A.A. Elfarra, Characterization of the methionine S-oxidase activity of rat liver and kidney microsomes: Immunochemical and kinetic evidence for FMO3 being the major catalyst, Arch. Biochem. Biophys. 333 (1996) 109-116.

[19] N. Lomri, Z. Yang, J.R. Cashman, Expression in Escherichia coli of the flavin-containing monooxygenase D (Form II) from adult human liver: Determination of a distinct tertiary amine substrate specificity, Chem. Res. Toxicol. 6 (1993) 425-429.

[20] A.E. Rettie, M.P. Lawton, A.J.M. Sadeque, G.P. Meier, R.M. Philpot, Prochiral sulfoxidation as a probe for multiple forms of the microsomal flavin-containing monooxygenase: Studies with rabbit FMO1, FMO2, FMO3 and FMO5 expressed in Escherichia coli, Arch. Biochem. Biophys. 311 (1994) 369-377.

[21] J.R. Cashman, Z. Yang, L. Yang, S.A. Wrighton, Stereo- and regio-selective N- and S-oxidation of tertiary amines and sulfides in the presence of adult human liver microsomes, Drug Metab. Dispos. 21 (1993) 492-501.

[22] A.J.M. Sadeque, A.C. Eddy, G.P. Meier, A.E. Rettie, Stereoselective sulfoxidation by human flavin-containing monooxygenase: catalytic diversity between hepatic fetal and renal forms, Drug Metab. Dispos. 20 (1992) 832-839.

[23] L.H. Overby, A.R. Buckpitt, M.P. Lawton, E. Atta-Asafo-Adjei, J. Schulze, R.M. Philpot, Characterization of flavin-containing monooxygenase five (FMO5) from human and guinea pig: Evidence that the unique catalytic properties of FMO5 are not confined to the rabbit ortholog, Arch. Biochem. Biophys. 317 (1995) 275-284.

[24] C.T. Dolphin, E.A. Cullingford, E.A. Shephard, R.L. Smith, I.R. Phillips, Differential developmental and tissue-specific regulation of expression of the genes encoding three members of the flavin-containing monooxygenase family of man, FMO1, FMO3, and FMO4, Eur. J. Biochem. 235 (1996) 683-689.

[25] A.P. Feinberg, B. Vogelstein, A technique for radiolabeling DNA restriction endonuclease fragments to high specific activity, Anal. Biochem. 132 (1983) 6-13.

[26] F. Sanger, S. Nicklen, A.R. Coulsen, DNA sequencing with chain terminating inhibitors, Proc. Natl. Acad. Sci. USA 74 (1977) 5463-5467.

[27] J. Devereux, P. Haeberli, O. Smithies, A comprehensive set of sequence analysis programs for the VAX, Nucleic Acids Res. 12 (1984) 387-395.

[28] K. Itagaki, G.T. Carver, R.M. Philpot, Expression and characterization of a modified flavin-containing monooxygenase 4 from humans, J. Biol. Chem. 271 (1996) 20102-20107.

[29] S.J. Pernecky, J.R. Larson, R.M. Philpot, M.J. Coon, Expression of truncated forms of liver microsomal P450 cytochromes 2B4 and 2E1 in Escherichia coli: Influence of $\mathrm{NH}_{2}$-terminal region on localization in cytosol and membranes, Proc. Natl. Acad. Sci. USA 90 (1993) 2651-2655.

[30] M.P. Lawton, R.M. Philpot, Functional characterization of flavin-containing monooxygenase 1B1 expressed in Saccharomyces cerevisiae and Escherichia coli and analysis of proposed FAD- and membrane-binding domains, J. Biol. Chem. 268 (1993) 5728-5734.

[31] A. Dixit, T.E. Roche, Spectrophotometric assay of the flavin-containing monooxygenase and changes in its activity in female mouse liver with nutritional and diurnal conditions, Arch. Biochem. Biophys. 233 (1984) 50-63.

[32] R. Gasser, M. Negishi, R.M. Philpot, Primary structures of multiple forms of cytochrome P-450 isozyme 2 derived from rabbit pulmonary and hepatic cDNAs, Mol. Pharmacol. 32 (1988) 22-30.

[33] J.M. Chirgwin, A.E. Przybyla, R.J. MacDonald, W.J. Rutter, Isolation of biologically active ribonucleic acid from sources enriched in ribonuclease, Biochemistry 18 (1979) 5294-5299.

[34] V. Glisin, R. Crkvenjakov, C. Byus, Ribonucleic acid isolated by cesium chloride centrifugation, Biochemistry 13 (1974) 2633-2637.

[35] H. Aviv, P. Leder, Purification of biologically active globin messenger RNA by chromatography on oligothymidylic acid-cellulose, Proc. Natl. Acad. Sci. USA 69 (1972) 1408-1412. 
[36] J.M. Bailey, N. Davidson, Methylmercury as a reversible denaturing agent for agarose gel electrophoresis, Anal. Biochem. 70 (1976) 75-85.

[37] U.K. Laemmli, M. Favre, Maturation of the head of bacteriophage T4 I. DNA packaging events, J. Mol. Biol. 80 (1973) 575-599.

[38] H. Towbin, T. Staehelin, J. Gordon, Electrophoretic transfer of proteins from polyacylamide gels to nitrocellulose sheets: procedure and some applications, Proc. Natl. Acad. Sci. USA 76 (1979) $4350-4354$.

[39] E.J. Faeder, L.M. Siegel, A rapid micromethod for determination of FMN and FAD mixtures, Anal. Biochem. 53 (1973) 332-336.

[40] O.H. Lowry, N.J. Rosebrough, A.L. Farr, R.J. Randall, Protein measurement with Folin phenol reagent, J. Biol. Chem. 193 (1951) 265-275.

[41] S.A. Wrighton, M. Vandenbranden, J.C. Stevens, L.A. Shipley, B.J. Ring, A.E. Rettie, J.R. Cashman, In vitro methods for assessing human hepatic drug metabolism: their use in drug development, Drug Metabol. Rev. 25 (1993) 453-484.

[42] B.A. Domin, C.J. Serabjit-Singh, R.M. Philpot, Quantitation of rabbit cytochrome P-450, form 2, in microsomal preparations bound directly to nitrocellulose paper using a modified peroxidaseimmunostaining procedure, Anal. Biochem. 136 (1984) 390-396.

[43] D.M. Cross, A consideration of the enzymology underlying ranitidine metabolism and drug interactions, J. Biopharm. Sci. 2 (1991) 339-377.

[44] N. Lomri, Z. Yang, J.R. Cashman, Regio-and stereo-selective oxygenations by adult human liver flavin-containing monooxygenase 3. Comparison with forms 1 and 2, Chem. Res. Toxicol. 6 (1993) $800-807$.

[45] E. Atta-Asafo-Adjei, M.P. Lawton, R.M. Philpot, Cloning, sequencing, distribution and expression of a mammalian flavin-containing monooxygenase from a third gene subfamily, J. Biol. Chem. 268 (1993) 9681-9689.

[46] N. Lomri, Z. Yang, J.R. Cashman, Expression in Escherichia coli of the flavin-containing monooxygenase D (Form II) from adult human liver: Determination of a distinct tertiary amine substrate specificity, Chem. Res. Toxicol. 6 (1993) 425-429. 